\title{
Microstructure and Mechanical Properties Evolution of the Al, C-Containing CoCrFeNiMn-Type High-Entropy Alloy during Cold Rolling
}

\author{
Margarita Klimova ${ }^{1}$, Nikita Stepanov ${ }^{1, *}$ (D), Dmitry Shaysultanov ${ }^{1}$, Ruslan Chernichenko ${ }^{1}$, \\ Nikita Yurchenko ${ }^{1}$, Vladimir Sanin ${ }^{2}$ and Sergey Zherebtsov ${ }^{1}$ \\ 1 Laboratory of Bulk Nanostructured Materials, Belgorod State University, Belgorod 308015, Russia; \\ klimova_mv@bsu.edu.ru (M.K.); shaysultanov@bsu.edu.ru (D.S.); rus.chernichenko@mail.ru (R.C.); \\ yurchenko_nikita@bsu.edu.ru (N.Y.); zherebtsov@bsu.edu.ru (S.Z.) \\ 2 Institute of Structural Macrokinetics and Materials Science, Russian Academy of Sciences, \\ Moscow 142432, Russian; svn@ism.ac.ru \\ * Correspondence: stepanov@bsu.edu.ru; Tel.: +7-472-258-5416
}

Received: 11 December 2017; Accepted: 28 December 2017; Published: 29 December 2017

\begin{abstract}
The effect of cold rolling on the microstructure and mechanical properties of an Al- and C-containing CoCrFeNiMn-type high-entropy alloy was reported. The alloy with a chemical composition (at \%) of (20-23) $\mathrm{Co}, \mathrm{Cr}, \mathrm{Fe}$, and Ni; $8.82 \mathrm{Mn}$; $3.37 \mathrm{Al}$; and $0.69 \mathrm{C}$ was produced by self-propagating high-temperature synthesis with subsequent induction. In the initial as-cast condition the alloy had an face centered cubic single-phase coarse-grained structure. Microstructure evolution was mostly associated with either planar dislocation glide at relatively low deformation during rolling (up to $20 \%$ ) or deformation twinning and shear banding at higher strain. After $80 \%$ reduction, a heavily deformed twinned/subgrained structure was observed. A comparison with the equiatomic CoCrFeNiMn alloy revealed higher dislocation density at all stages of cold rolling and later onset of deformation twinning that was attributed to a stacking fault energy increase in the program alloy; this assumption was confirmed by calculations. In the initial as-cast condition the alloy had low yield strength of $210 \mathrm{MPa}$ with yet very high uniform elongation of $74 \%$. After $80 \%$ rolling, yield strength approached $1310 \mathrm{MPa}$ while uniform elongation decreased to $1.3 \%$. Substructure strengthening was found to be dominated at low rolling reductions $(<40 \%)$, while grain (twin) boundary strengthening prevailed at higher strains.
\end{abstract}

Keywords: high-entropy alloys; microstructure evolution; twinning; mechanical properties; strengthening mechanisms

\section{Introduction}

High-entropy alloys (HEAs) have recently emerged as new class of metallic materials with properties attractive for various structural and functional applications [1-4]. In particular, different HEAs demonstrate high strength and/or ductility at room and cryogenic temperatures, high specific strength at elevated temperatures, excellent fracture and impact toughness, wear resistance, etc. [5-18]. Producing HEAs with a balanced combination of properties needed for practical applications still remains a significant challenge, however.

Alloys based on the transition elements are the most studied type of HEAs [1]. One of the typical representatives of such HEAs is the equiatomic CoCrFeNiMn alloy [19-21]. This alloy has a single face centered cubic (fcc) phase structure thermodynamically stable at temperatures $\geq 900{ }^{\circ} \mathrm{C}$ [22-24]. It has very high ductility (70-80\%) at both room and cryogenic temperatures, and record breaking fracture toughness under cryogenic conditions [5,9]. The encouraging properties of the alloy at cryogenic 
temperature were mostly attributed to pronounced deformation nano-twinning promoting high strain hardening capacity $[5,9,25]$. However, there are still different opinions on relative contributions of dislocation slip and twinning during plastic deformation at room temperature [9,26-29].

Apparently, mechanical properties of the CoCrFeNiMn alloy can be improved either by thermomechanical processing (resulting in a microstructure modification) or by alloying (changing the chemical composition). Both options have been explored by researchers already. For instance, it was found that cold rolling of the $\mathrm{CoCrFeNiMn}$ resulted in a considerable increase in strength with a simultaneous decrease in ductility [27]; however, microstructure refinement due to recrystallization can result in higher strength without a loss in ductility $[9,30]$. Doping with other elements (as well as changes in the concentrations of the principal elements) can be used either to enhance solid solution strengthening while maintaining a single phase solid solution structure and/or to cause the formation of second phases and to increase the strength via precipitation strengthening [10,31-39]. Both substitutional (an effective example is $\mathrm{Al}$ [38]) and interstitial (like C [31]) solid solution strengthening can be utilized.

However, modifications of the chemical composition of the fcc solid solution can also result in changes of different strengthening mechanisms activity. For example, intensive deformation twinning in the $\mathrm{CoCrFeNiMn}$ alloy was usually ascribed to a considerable decrease in the stacking fault energy (SFE) values to $20-30 \mathrm{~mJ} \cdot \mathrm{m}^{-2}$ [40,41]; an increase in the SFE values due to alloying can result in twinning suppression that inevitably would have a pronounced effect on the mechanical behavior of the alloys. It has been established earlier that $\mathrm{Al}$ and $\mathrm{C}$ in austenitic $(\mathrm{fcc})$ steels are among the elements that strongly increase the SFE, thereby promoting dislocation slip and suppressing twinning [42-44]. However, there are contradicting reports on the effect of carbon doping on deformation mechanisms operating in the Co-Cr-Fe-Ni-Mn system high entropy alloys [12,32,33,45]. The effect of $\mathrm{Al}$ is even much less studied, however, deformation twinning was reported for the Al0.1CoCrFeNi alloy, nominally containing 2.4 at $\%$ of $\mathrm{Al}[46,47]$. Therefore, additional studies on the effects of alloying on deformation mechanisms of the CoCrFeNiMn-type alloys are required.

To explore operating deformation mechanisms, microstructure evolution during rolling and tensile properties of the CoCrFeNiMn-type HEA, containing $~ 3.4$ at $\%$ of $\mathrm{Al}$ and $\sim 0.7$ at $\%$ of $\mathrm{C}$ was studied in detail. The following main aims were pursued: (i) to establish active deformation mechanisms at different stages of plastic deformation; and (ii) to estimate, quantitatively, the contributions of different strengthening mechanisms during cold working. Only a limited number of thorough investigations of this kind on HEAs have been made so far [27,34,48-50].

\section{Results}

\subsection{Microstructure of the Al-, C-Containing CoCrFeNiMn-Type Alloy in the as-Cast Condition}

Figure 1 illustrates the microstructure of the Al-, C-containing CoCrFeNiMn-type alloy in the initial as-cast condition. Both the X-ray diffraction (XRD) pattern (Figure 1a) and electron backscattered diffraction (EBSD) inverse pole figure (IPF) map (Figure 1b) demonstrated the presence of a single phase with the fcc lattice. According to the XRD results, the fcc lattice parameter a was $3.588 \mathrm{~nm}$. In addition, both the XRD and EBSD data revealed strong crystallographic texture, typical for the cast materials. The alloy had a coarse structure with a grain size of $250-400 \mu \mathrm{m}$. Grains of irregular shape were often surrounded by curved boundaries. Additional investigations by scanning electron microscopy (SEM) and transmission electron microscopy (TEM) (not shown) have also not revealed the presence of any second phases. The chemical composition of the grains determined by SEM-based energy-dispersive X-ray spectroscopy (EDX) strictly corresponded to the composition of the alloy (Table 1). 


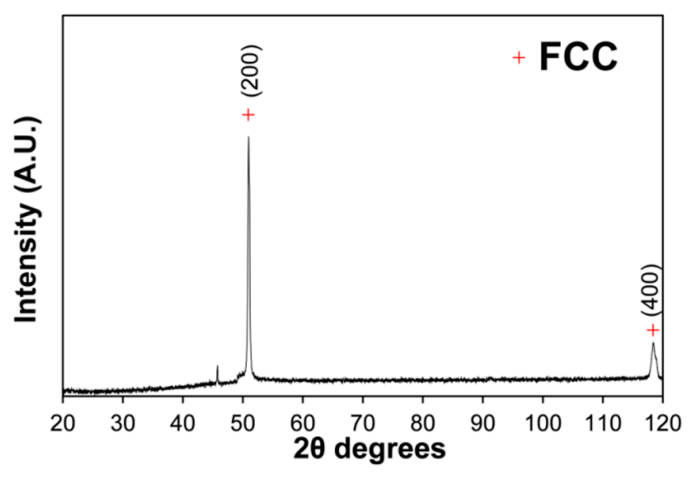

(a)

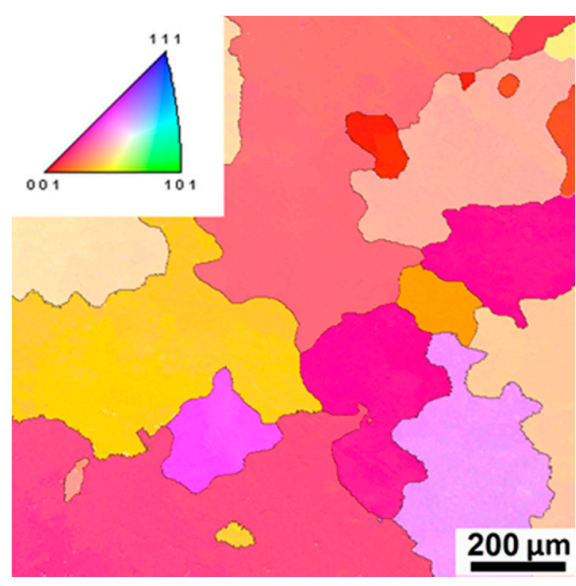

(b)

Figure 1. Structure of the Al-, C-containing CoCrFeNiMn-type alloy in the as-cast condition: (a) XRD pattern; and (b) EBSD IPF map.

Table 1. Chemical composition of the Al-, C-containing CoCrFeNiMn-type alloy.

\begin{tabular}{cccccccc}
\hline Concentration & Al & C & Co & Cr & Fe & Ni & Mn \\
\hline at $\%$ & 3.37 & 0.69 & 22.35 & 19.67 & 22.85 & 22.44 & 8.62 \\
wt. \% & 1.65 & 0.15 & 23.92 & 18.57 & 23.17 & 23.92 & 8.64 \\
\hline
\end{tabular}

\subsection{Microstructure Evolution of the Al-, C-Containing CoCrFeNiMn-Type Alloy during Cold Rolling}

EBSD IPF maps (Figure 2) shows microstructure evolution of the Al-, C-containing $\mathrm{CoCrFeNiMn-type} \mathrm{alloy} \mathrm{during} \mathrm{cold} \mathrm{rolling.} \mathrm{Noticeable} \mathrm{changes} \mathrm{in} \mathrm{the} \mathrm{microstructure} \mathrm{were} \mathrm{observed}$ only for $\varepsilon=20 \%$ (Figure $2 \mathrm{a}$ ). After $20 \%$ thickness reduction the development of a banded substructure inside initial grains was observed (Figure 2a). With an increase in rolling strain, the initial grains elongated towards the rolling direction (Figure $2 b$ ). The grains were subdivided by deformation bands (dark areas in Figure 2b). The development of deformation twinning in some grains was also observed (higher magnification insert in Figure 2b). At yet higher rolling reduction (60\%) more extensive development of twinning was found (Figure 2c). However, even after rolling to the highest strain of $80 \%$ some areas with only dislocation substructure were observed (Figure $2 \mathrm{~d}$ ). Twin boundaries and deformation bands aligned along the rolling direction with an increase in rolling reduction.

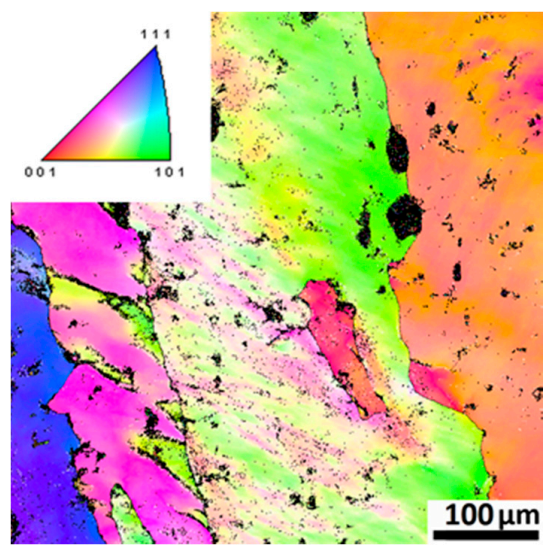

(a)

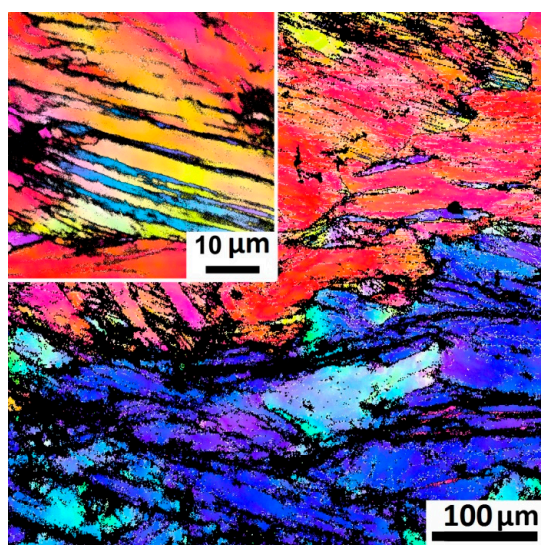

(b)

Figure 2. Cont. 


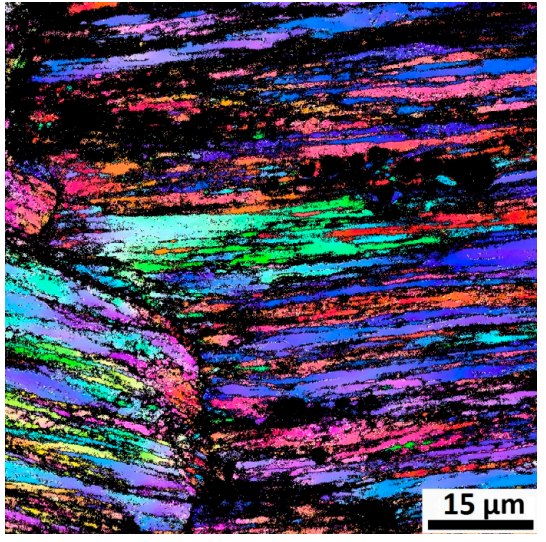

(c)

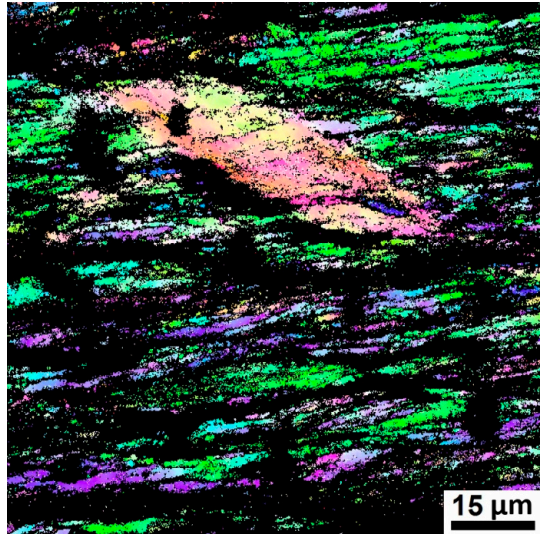

(d)

Figure 2. EBSD IPF maps of the Al-, C-containing CoCrFeNiMn-type alloy after cold rolling with different thickness reduction: (a) 20\%; (b) 40\%; (c) 60\%; and (d) $80 \%$. Rolling direction is aligned with the horizontal axis.

TEM investigations revealed additional insights into the evolution of the microstructure of the $\mathrm{Al}-, \mathrm{C}-\mathrm{containing} \mathrm{CoCrFeNiMn-type} \mathrm{alloy} \mathrm{(Figure} \mathrm{3).} \mathrm{Pronounced} \mathrm{dislocation} \mathrm{activity} \mathrm{was} \mathrm{observed}$ at the initial stages of deformation (Figure 3a). Dislocation slip was planar (Figure 3b); intersection of slip bands was found at higher strains (Figure 3c). Some individual, relatively thick twins started to appear at the same time (Figure 3d). High dislocation density inside twins should be noted. At $40 \%$ of thickness reduction intensive twinning was observed (Figure 3e). Deformation twins belonged to the $(111)<112>$ family (twin/matrix misorientation of $60^{\circ}$ around $<111>$ ) (insert on Figure 3e). The fraction of deformation twins obviously increased with further strain (Figure 3f). However, some areas comprised of only dislocation pile-ups and subboundaries were also observed. The formation of shear bands occurred concurrently (highlighted with the arrows in Figure 3f). As the result after $80 \%$ rolling inhomogeneous microstructure composed of twinned and subgrained areas was formed (Figure 3g).

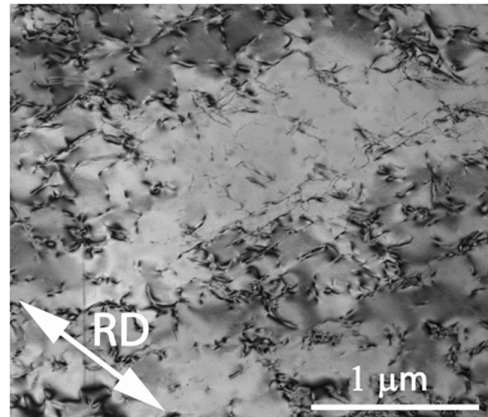

(a)

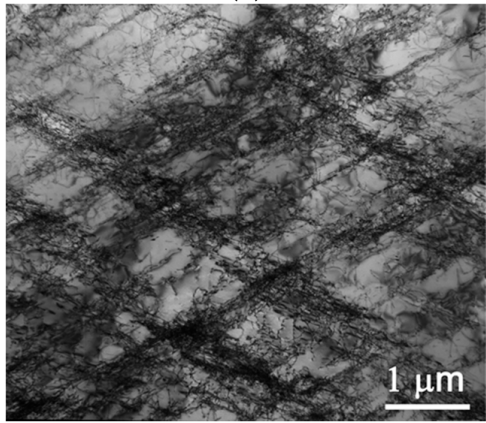

(c)

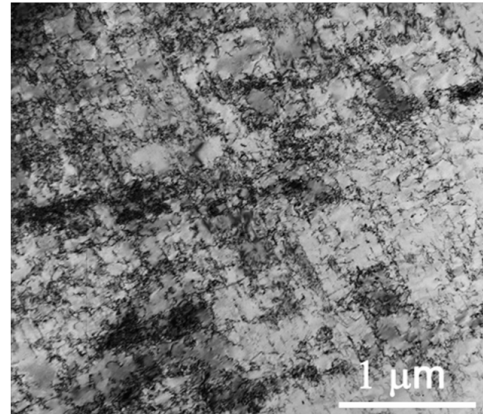

(b)

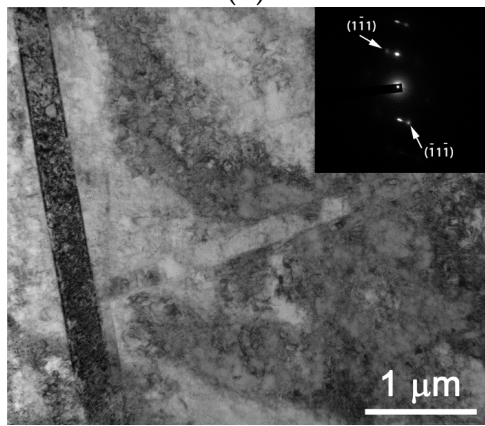

(d)

Figure 3. Cont. 


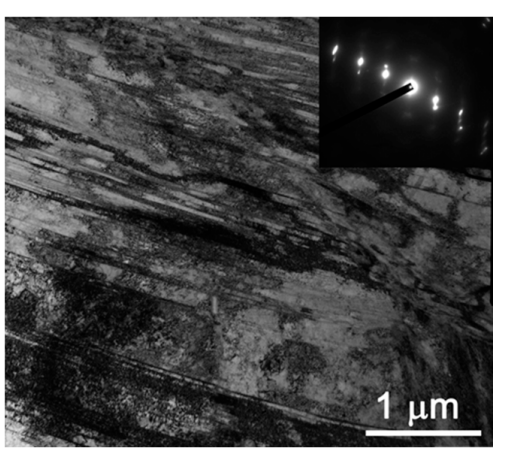

(e)

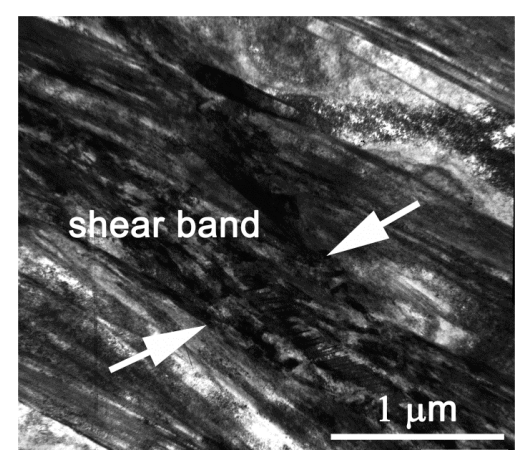

(f)

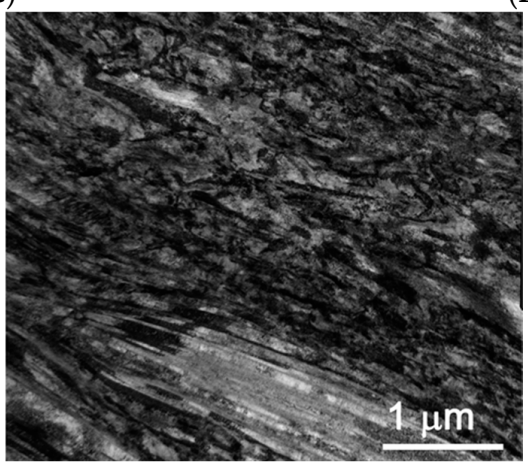

(g)

Figure 3. TEM bright-field images of the microstructure of the Al-, C-containing CoCrFeNiMn-type alloy after rolling with different thickness reduction: (a) 5\%; (b) 10\%; (c,d) 20\%; (e) 40\%; (f) 60\%; and (g) $80 \%$. Rolling direction (RD) is identified with the arrow in Figure $3 a$.

Quantitative analysis (Figure 4) of microstructure evolution of the Al-, C-containing CoCrFeNiMn-type alloy generally confirmed the results obtained by EBSD and TEM. Dislocation density increased relatively quickly at the initial stages of strain; from $\sim 1 \times 10^{11} \mathrm{~m}^{-2}$ in the initial condition to $\sim 2 \times 10^{15} \mathrm{~m}^{-2}$ after $40 \%$ strain (Figure $4 \mathrm{a}$ ). At further rolling the increase in the dislocation density become much slower. Note that in the reference $\mathrm{CoCrFeNiMn}$ the overall dependence of dislocation density on rolling strain was similar, however, the "saturation" stage was reached already after $25 \%$ reduction, and dislocation densities at the same or comparable rolling strains were ca. two times lower than those in the present alloy. On the other hand, twinning obviously occurred much earlier in the reference $\mathrm{CoCrFeNiMn}$ alloy in comparison with the $\mathrm{Al}$-, C-containing CoCrFeNiMn-type alloy: The first twins were detected only after $20 \%$ rolling reduction (Figure $4 \mathrm{~b}$, see also Figure 3d). However, twinning was developed extremely fast and already after $40 \%$ strain almost all grains were twinned (see also Figure $2 b$ ). Note that the development of twinning resulted in a sharp decrease in spacing between boundaries in the $\mathrm{Al}-$, C-containing CoCrFeNiMn-type alloy at strains $\geq 40 \%$ (Figure $4 \mathrm{c}$ ). The inter-twin distances attained values of about $0.06 \mu \mathrm{m}$ at $\varepsilon=80 \%$. In the reference $\mathrm{CoCrFeNiMn}$ alloy the spacing between boundaries decreased much faster due to earlier onset of twinning. 


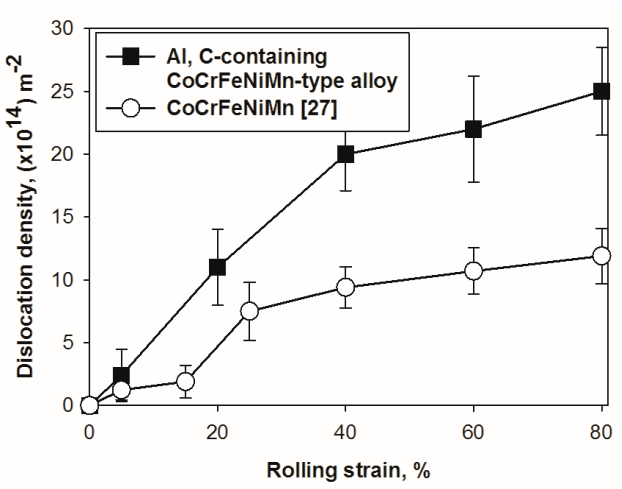

(a)

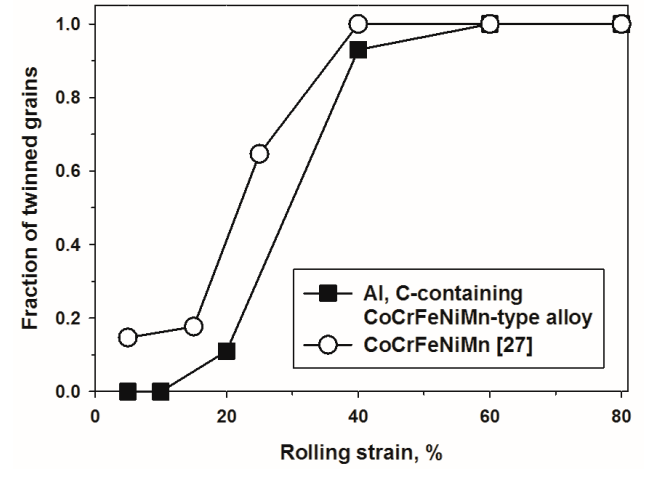

(b)

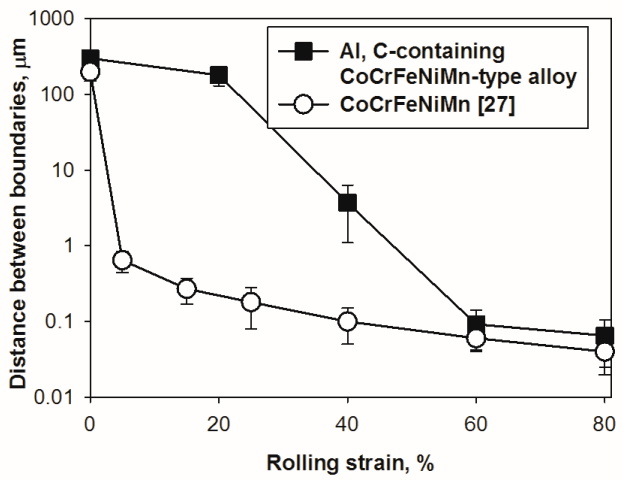

(c)

Figure 4. Dependence of (a) dislocation density; (b) fraction of twinned grains; and (c) distance between boundaries of the Al-, C-containing CoCrFeNiMn-type alloy on rolling strain. Data for the equiatomic CoCrFeNiMn alloy [27] is shown for comparison.

\subsection{Mechanical Properties of the Al-, C-Containing CoCrFeNiMn-Type Alloy}

Figure 5 shows microhardness evolution of the Al-, C-containing CoCrFeNiMn-type alloy during rolling. In the initial as-cast condition the hardness of the Al-, C-containing alloy was $173 \mathrm{HV}_{0.3}$. During cold rolling the hardness of the alloy increased rapidly to $280 \mathrm{HV}_{0.3}$ after $\varepsilon=20 \%$ and then, a bit slower, to $384 \mathrm{HV}_{0.3}$ after $\varepsilon=60 \%$. A further increase in strain to $80 \%$ did not result in noticeable changes in microhadness. The microhardness evolution of the $\mathrm{Al}, \mathrm{C}$-containing CoCrFeNiMn-type alloy is similar to that of the $\mathrm{Al}-, \mathrm{C}$-free $\mathrm{CoCrFeNiMn}$ alloy, yet the microhadness values of the present alloy were $\approx 20-40 \mathrm{HV}_{0.3}$ higher than that of the reference alloy.

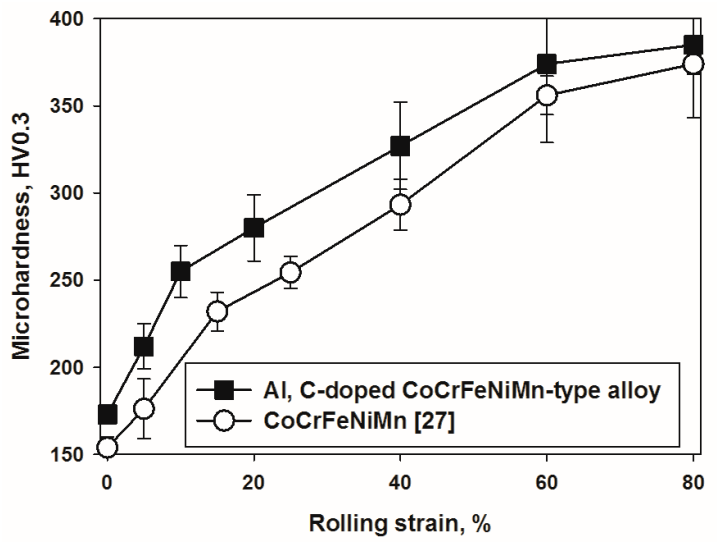

Figure 5. The dependence of microhardness of the Al-, C-containing CoCrFeNiMn-type alloy on rolling strain. Data for the equiatomic CoCrFeNiMn alloy [27] is shown for the comparison. 
More detailed understanding of the effect of cold rolling on mechanical properties of the Al-, C-containing CoCrFeNiMn-type alloy can be obtained via tensile tests. The representative stress-strain curves are shown in Figure 6, and the mechanical properties, namely yield strength $\left(\sigma_{0.2}\right)$, ultimate tensile strength $\left(\sigma_{\mathrm{UTS}}\right)$, uniform elongation $\left(\varepsilon_{\mathrm{u}}\right)$, and elongation to fracture $\left(\varepsilon_{\mathrm{f}}\right)$, are summarized in Table 2. The as-cast alloy demonstrated low yield strength of $210 \mathrm{MPa}$ with a pronounced hardening stage resulting in very high uniform elongation of $74 \%$. The ultimate tensile strength and elongation to fracture of the cast alloy were $455 \mathrm{MPa}$ and $80 \%$, respectively. Rolling to relatively small thickness reduction $(\varepsilon=20 \%)$ resulted in pronounced hardening; the yield strength and ultimate tensile strength increased to $545 \mathrm{MPa}$ and $650 \mathrm{MPa}$, respectively. However, the work hardening capacity of the alloy became lower with strain. Thus, the uniform elongation and elongation to fracture decreased to $18 \%$ and $25 \%$, respectively. A further increase in rolling reduction to $40 \%$ increased strength and pronouncedly decreased ductility. The ultimate tensile strength of the alloy cold rolled to $\varepsilon=40 \%$ was found to be $980 \mathrm{MPa}$, while the uniform and total elongations were $3.7 \%$ and $7 \%$, respectively. Rolling to higher strains resulted in even more pronounced hardening. For example, the ultimate tensile strength of the alloy was $1140 \mathrm{MPa}$ and $1500 \mathrm{MPa}$ after rolling to $60 \%$ and $80 \%$ reduction, respectively. However, the strengthening was associated with a significant decrease in ductility. The uniform elongation of the $\mathrm{Al}, \mathrm{C}$-containing CoCrFeNiMn-type alloy after rolling to $60 \%$ and $80 \%$ strain was $2.3 \%$ and $1.3 \%$, respectively.

Strain hardening of the alloy in the initial as-cast condition (Figure $6 \mathrm{~b}$ ) was characterized by a reduction in hardening at the initial stage of deformation (to the true strain of 0.05 ) further increasing to the true strain of $\sim 0.55$, and then dropping to zero. The alloy after $20 \%$ rolling does not show any increase in the $\mathrm{d} \sigma / \mathrm{d} \varepsilon$ values during deformation, however, a lower rate of strain hardening decreasing can be seen in the interval of strains $0.05-0.2$. All specimens of the alloy rolled to $40-80 \%$ (only one of them is shown in Figure 6b) demonstrate a sharp drop in strain hardening almost immediately after the beginning of deformation.

Table 2. Tensile properties of the Al-, C-containing CoCrFeNiMn-type alloy in different conditions.

\begin{tabular}{ccccc}
\hline Condition & $\boldsymbol{\sigma}_{\mathbf{0 . 2}}, \mathbf{M P a}$ & $\boldsymbol{\sigma}_{\mathbf{U T S}}, \mathbf{M P a}$ & $\boldsymbol{\varepsilon}_{\mathbf{u}}, \boldsymbol{\%}$ & $\boldsymbol{\varepsilon}_{\mathbf{f}}, \boldsymbol{\%}$ \\
\hline As-cast & 210 & 455 & 74.0 & 80.0 \\
20\% rolling & 545 & 650 & 18.0 & 25.0 \\
$40 \%$ rolling & 945 & 980 & 3.7 & 7.0 \\
60\% rolling & 1110 & 1140 & 2.3 & 5.4 \\
80\% rolling & 1310 & 1500 & 1.3 & 6.5 \\
\hline
\end{tabular}

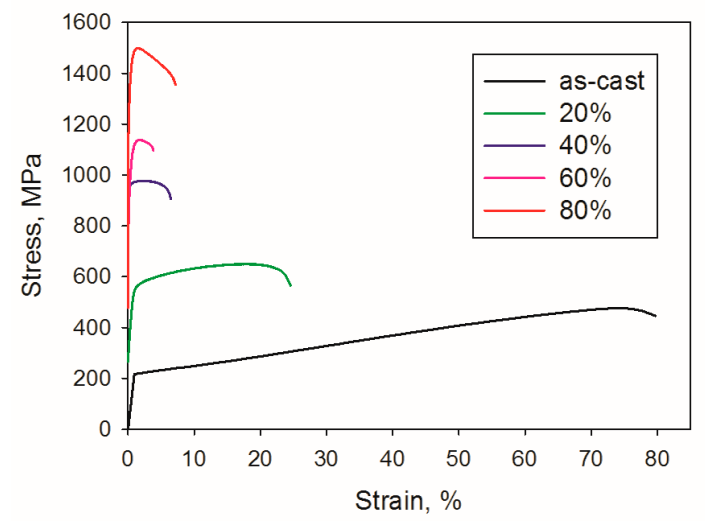

(a)

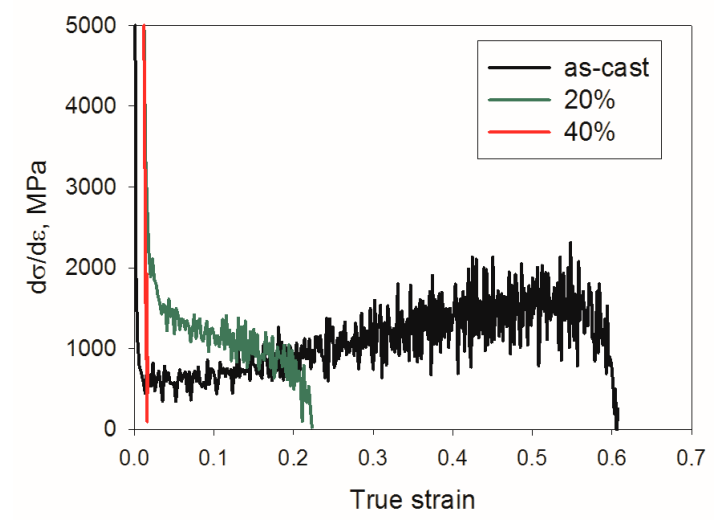

(b)

Figure 6. (a) Tensile stress-strain curves and (b) strain hardening curves of the Al-, C-containing CoCrFeNiMn-type alloy in the as-cast condition and after cold rolling with different thickness reductions. 


\section{Discussion}

The main features of the microstructure evolution of the Al-, C-containing CoCrFeNiMn-type high-entropy alloy during cold rolling comprised planar dislocation slip followed by intensive twinning and pronounced formation of shear bands (Figures 2-4). The same mechanisms were found to operate in the reference equiatomic CoCrFeNiMn alloy [27], however, relative contributions of these mechanisms at different stages were pronouncedly different (Figure 4). Changes of deformation mechanisms in the fcc metals can be associated with the value of the stacking fault energy. However the exact calculation of the SFE value (which is a complex function of chemical composition of the alloy) is a very intricate problem. This value cannot be evaluate on the basis of already known data (for example the SFE for the equiatomic CoCrFeNiMn is known to be $20-30 \mathrm{~mJ} \cdot \mathrm{m}^{-2}$ ) since the composition of the program alloy differs from the classic equiatomic Cantor's alloy both by the presence of $\mathrm{Al}$ and $\mathrm{C}$ and by concentrations of principal elements (Table 1).

A relatively simple approach to estimate the SFE of Fe-Mn steels was proposed in [51,52]. According to this approach, the SFE values can be calculated in accordance to the following formula:

$$
\gamma_{\mathrm{SFE}}=2 \rho \Delta \mathrm{G}_{\mathrm{hcp}-\mathrm{fcC}}+2 \sigma
$$

where $\gamma_{\mathrm{SFE}}$ is the SFE value, $\Delta \mathrm{G}_{\mathrm{hcp}-\mathrm{fcc}}$ is the difference in Gibbs free energy between the hexagonal close packed (hcp) and fcc phases, $\rho$ is the number of atoms per $\mathrm{m}^{2}$ in one atomic layer, and $\sigma$ is the interphase energy between the fcc and hcp phases. Given the already-reported similarity in composition, structure, and mechanical behavior of the Co-Cr-Fe-Ni-Mn high-entropy alloys and high-Mn twinning-induced plasticity (TWIP) steels [27,53,54], Equation (1) was adapted in the present work to evaluate the difference in the SFEs between the reference Cantor's CoCrFeNiMn alloy and the program Al-C-containing alloy. For this purpose, the $\Delta \mathrm{G}_{\mathrm{hcp}-\mathrm{fcc}}$ values were calculated in both alloys using CALPHAD approach and commercial Thermo-Calc software (v. 2017a, Thermo-Calc Software, Stockholm, Sweden) and TCHEA2 database. Actual (Table 1) chemical composition of the Al-, C-containing alloy and nominal values (i.e., 20 at \% of each element) of the CoCrFeNiMn alloys were used. The calculations were performed for room temperature $\left(20^{\circ} \mathrm{C}\right)$. The obtained results were values of $\Delta \mathrm{G}_{\mathrm{hcp}-\mathrm{fcc}}=0.72 \mathrm{~kJ} / \mathrm{mol}$ for the reference CoCrFeNiMn alloy and $0.98 \mathrm{~kJ} / \mathrm{mol}$ for the studied Al-, C-containing alloy. Although further exact calculations of the SFE were complicated due to the absence of other input values for Equation (1), the comparison of the calculated $\Delta \mathrm{G}_{\mathrm{hcp}-\mathrm{fcc}}$ values clearly suggests that SFE of the Al-, C-containing alloy is higher than its CoCrFeNiMn equiatomic counterpart.

The increase in the SFE energy can perfectly explain the retardation of twinning in the Al-, C-containing CoCrFeNiMn-type alloy (Figure 4a). Greater SFE resulted in higher stresses required for twinning initiation; thus, the onset of deformation in the program alloy was generally associated with slip promoting a more intensive increase in dislocation density. The activation of twinning occurs when the flow stress of the material increases due to strain hardening. Since the strain hardening behavior of both alloys (Figure 5) is more or less similar, the required stress level reached at later stages of deformation in the $\mathrm{Al}, \mathrm{C}$-containing alloy in comparison with the equiatomic counterpart. Due to mainly planar slip (Figure $2 \mathrm{~b}, \mathrm{~d}$ ), recovery is limited and therefore dislocation density in the $\mathrm{Al}$, $\mathrm{C}$-containing alloy remains to be very high. Note that strongly planar slip was also found in high-Mn steels with higher SFE than the TWIP steels (the-called low-density steels) $[55,56]$.

Microstructure evolution during rolling obviously impacts the mechanical properties (Figures 5 and 6, Table 2). Both an increase in dislocation density and decrease in boundary spacing, mostly due to mechanical twinning (Figure $4 \mathrm{a}, \mathrm{c}$, respectively) can contribute to the strengthening of the alloy during deformation. The overall strength of the alloy can be expressed as:

$$
\sigma=\sigma_{0}+\sigma_{\rho}+\sigma_{H-P}
$$

where $\sigma_{0}$ denotes the friction stress, $\sigma_{\rho}$ is the substructure strengthening, expressed as: 


$$
\sigma_{\rho}=\mathrm{M} \alpha \mathrm{Gb} \sqrt{\rho}
$$

and $\sigma_{\mathrm{H}-\mathrm{P}}$ is the Hall-Petch strengthening:

$$
\sigma_{\mathrm{H}-\mathrm{P}}=\mathrm{K}_{\mathrm{y}} \mathrm{d}^{-1 / 2}
$$

In these equations $M$ is the Taylor factor, $\alpha$ is a constant, $G$ is the shear modulus, $b$ is the Burgers vector, and $\rho$ is the dislocation density; $K_{y}$ is the Hall-Petch coefficient and $d$ is the grain size (boundary spacing).

In the present work the following parameters were used: $M=2, \alpha=0.2, G=80$ GPa [57], $\mathrm{b}=2.58 \times 10^{-10} \mathrm{~m}$ [27]. The value of $\sigma_{0}=210 \mathrm{MPa}$ was used in accordance with the experimental yield strength of the alloy in the initial coarse-grained condition (Table 2). The value of the Hall-Petch coefficient was experimentally determined as $\mathrm{K}_{\mathrm{y}}=0.4 \mathrm{MPa} \cdot \mathrm{m}^{-1 / 2}$ for arbitrary grain boundaries. Twice lower $\mathrm{K}_{\mathrm{y}}$ of $0.2 \mathrm{MPa} \cdot \mathrm{m}^{-1 / 2}$ was used for twin boundaries (rolling reduction $\geq 40 \%$ ) in accordance with the results of [58]. The values calculated using the Equations (2)-(4) are shown in Figure 7. The $\rho$ and $d$ values for the calculations were taken from Figure $4 a$,c, respectively.

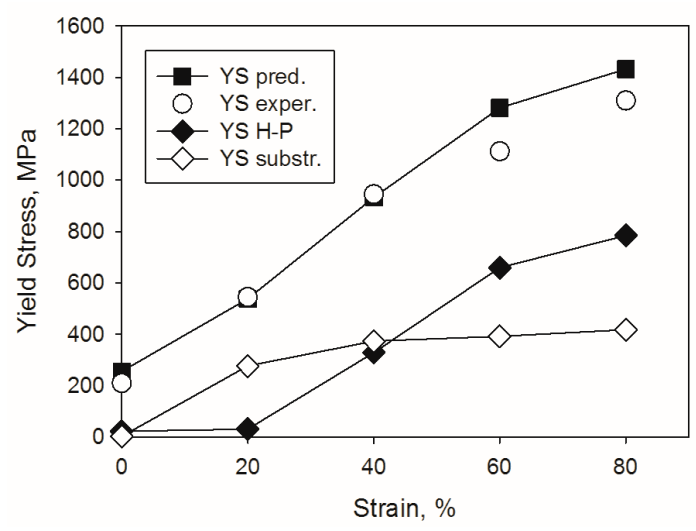

Figure 7. Contribution of different strengthening mechanisms to the overall strength of the Al-, C-containing CoCrFeNiMn-type alloy during rolling.

The comparison between the experimental and the calculated (Equation (2)) values demonstrates a very good fit, especially for strains $\varepsilon \leq 40 \%$ (Figure 7). More detailed analysis shows that at $\varepsilon=20 \%$ reduction, the strength increases mostly due to substructure hardening while Hall-Petch strengthening is negligible. However, a further increase in strain does not result in a pronounced increase in substructure strengthening due to the saturation of dislocation density at strains $\varepsilon \geq 40 \%$ (Figure $4 \mathrm{a}$ ). At the same time, grain boundary (Hall-Petch) strengthening grows continuously at $\varepsilon \geq 20 \%$ as a result of intensive twinning (Figure $4 \mathrm{~b}$ ). In general, the relative efficiency of the strengthening mechanisms operating in the $\mathrm{Al}-, \mathrm{C}$-containing $\mathrm{CoCrFeNiMn-type} \mathrm{alloy} \mathrm{is} \mathrm{in} \mathrm{good} \mathrm{agreement} \mathrm{with}$ microstructural observations (Figures 2-4). The main deformation mode at the first stage of rolling was dislocation slip. The contributions of substructure and grain boundary strengthening became nearly equal at rolling reduction of $40 \%$. During further deformation twinning makes the main contribution to deformation and Hall-Petch strengthening dominates due to the presence a large number of twin boundaries. Late development of deformation twinning resulted in rather specific shape of the strain hardening curve with increasing till the very end of deformation (Figure $6 \mathrm{~b}$ ). This result is quite similar to those obtained earlier for some TWIP steels [59] in which twinning proceeded during the greatest part of deformation. However, in such twinning alloys as commercially-pure titanium or brass, the stage of twinning-induced strain hardening growth is quite short and observed in the beginning of deformation [60]. Even small prestraining (in our case 20\% rolling, Figure 6a, see also [59]) suppresses the effect of twinning on strain hardening, thereby considerably decreasing the ductility of the alloy. 
It should be noted that in the equiatomic CoCrFeNiMn alloy dominant role of grain boundary strengthening within the whole (5-80\%) strain range was established [27]. This is most possibly associated with the already-discussed larger propensity of the equiatomic alloy to twinning.

\section{Materials and Methods}

The initial Al-, C-containing CoCrFeNiMn-type alloy was produced by self-propagating high-temperature synthesis (SHS). Mixture of powders (oxides of the target elements $\left(\mathrm{NiO}, \mathrm{Cr}_{2} \mathrm{O}_{3}\right.$, $\mathrm{Co}_{3} \mathrm{O}_{4}, \mathrm{Fe}_{2} \mathrm{O}_{3}, \mathrm{MnO}_{2}$ ), pure carbon (C), and $\mathrm{Al}$ as the metal reducer) was used as a starting material. The weight of the initial mixture for combustion was $1200 \mathrm{~g}$. Combustion was carried out in graphite molds $80 \mathrm{~mm}$ in diameter. Previous studies have demonstrated that the SHS process carried out under high-gravity conditions allows the best separation of the target product (ingot) from the slag $\left(\mathrm{Al}_{2} \mathrm{O}_{3}\right)$ and convective mixing of all alloy components, which becomes especially important with an increased number of components and their concentration of components in the alloy. Therefore, the synthesis of the alloy was carried out in a centrifugal SHS setup. The SHS-produced HEA was $600 \pm 10 \mathrm{~g}$ in weight and looked like a cast product. However, it contained numerous pores. Thus, the SHS-produced alloy was remelted using an induction furnace in vacuum and cast into an ingot measuring $\sim 40 \mathrm{~mm}$ in diameter and $\sim 80 \mathrm{~mm}$ in length. This was used as the starting condition. The chemical composition (metallic elements were determined by scanning electron microscope (SEM)-based energy-dispersive X-ray spectroscopy (EDX) scan using an FEI Nova NanoSEM 450 (ThermoFisher Scientific, Hillsboro, OR, USA) over the large area $(\sim 1 \times 1 \mathrm{~mm})$, carbon was measured by a Leco analyzer) is shown in Table 1.

Slabs with a thickness of $5 \mathrm{~mm}$ were cut from the ingot of the alloy by an electric discharge machine for further rolling. The slabs were rolled unidirectionally in a few passes at room temperature to a final thickness strain of $80 \%$. Samples with intermediate thickness strains of 5\%,10\%, 20\%, 40\%, and $60 \%$ were also produced. The reductions per pass were $5-10 \%$. The rolling strain was calculated from the thickness of produced specimens.

The structure of the alloy was studied using X-ray diffraction (XRD) analysis, transmission electron microscopy (TEM), and electron backscattered diffraction (EBSD) analysis. The XRD analysis was performed using a RIGAKU diffractometer (Rigaku Corporation, Tokyo, Japan) and Cu Ka radiation.

Microstructural investigations were carried out in the plane perpendicular to the transversal direction. EBSD was conducted in an FEI Nova NanoSEM 450 field-emission-gun scanning electron microscope (FEG-SEM) (ThermoFisher Scientific, Hillsboro, OR, USA) equipped with a Hikari EBSD detector (EDAX Inc., Mahwah, NJ, USA) and TSL OIM ${ }^{\mathrm{TM}}$ system version 6.0 (EDAX Inc., Mahwah, NJ, USA). The samples for EBSD analysis were prepared by careful mechanical polishing. The border between low-angle boundaries (LABs, shown with white lines on presented inverse pole figure (IPF) maps) and high-angle boundaries (HABs, shown with black lines) was assumed to be $15^{\circ}$. Misorientations below $2^{\circ}$ were not taken into consideration. The points with the confidence index (CI) below 0.1 were excluded from the analysis and were depicted as black dots on the presented IPF maps.

TEM investigations were performed using a JEOL JEM-2100 microscope (JEOL Ltd., Tokyo, Japan) with an accelerating voltage of $200 \mathrm{kV}$. The samples for the TEM analysis were prepared by conventional twin-jet electro-polishing of foils mechanically pre-thinned to $100 \mu \mathrm{m}$, in a mixture of $90 \% \mathrm{CH}_{3} \mathrm{COOH}$ and $10 \% \mathrm{HClO}_{4}$ at $30 \mathrm{~V}$ potential at room temperature. The dislocation density was estimated by counting the individual dislocations in the grains/subgrains interiors per unit area using TEM images.

To determine the post-rolling mechanical properties, tension tests were conducted at room temperature. For this purpose, dog-bone-shaped flat specimens with gauge dimensions of $5 \mathrm{~mm}$ length $\times 3 \mathrm{~mm}$ width $\times 1 \mathrm{~mm}$ thickness were machined and pulled to fracture at an initial strain rate of $10^{-3} \mathrm{~s}^{-1}$ using an Instron 5882 test machine (Instron, Norwood, MA, USA). At least two specimens were tested for each condition. Elongation to fracture was determined by measurements of spacing between marks designating the gauge length before and after the test. The microhardness of the rolled 
specimens was examined using Vickers microhardness (Instron, Norwood, MA, USA) testing with a load of $0.3 \mathrm{~kg}$. At least 20 individual measurements per condition were made and the mean values are presented.

\section{Conclusions}

In the present work, the microstructure and mechanical properties evolution of the Al-, C-containing CoCrFeNiMn-type high-entropy alloy during cold rolling was studied. The following conclusions were drawn:

(1) The alloy produced by self-propagating high-temperature synthesis and further induction remelting was composed of $\approx 20-23$ at \% of $\mathrm{Co}, \mathrm{Cr}, \mathrm{Fe}$, and $\mathrm{Ni}, 8.82$ at \% of $\mathrm{Mn}, 3.37$ at $\%$ of $\mathrm{Al}$, and 0.69 at $\%$ of $\mathrm{C}$. The as-cast alloy had a coarse-grained single fcc phase structure with a grain size of 250-400 $\mu \mathrm{m}$. The alloy had low yield strength of $210 \mathrm{MPa}$, but demonstrated a high uniform elongation of $74 \%$.

(2) At the initial stages of rolling (thickness reduction $<40 \%$ ) mostly planar dislocation glide took place. First deformation twins appeared at a rolling reduction of $20 \%$, and at $40 \%$ the strain of almost each grain contained at least one deformation twin. Formation of deformation twins resulted in a strong reduction of boundary spacing.

(3) A comparison with the equiatomic CoCrFeNiMn alloy demonstrated that dislocation density was $~ 2$ times higher in the investigated Al-, C-containing alloy while twinning has initiated at later stages of deformation ( $20 \%$ reduction vs. $5 \%$ in the equiatomic alloy). The changes in deformation mechanisms were attributed to an increase in the stacking fault energy, which was confirmed by the Thermo-Calc estimation of the $\Delta \mathrm{G}_{\mathrm{hcp}-\mathrm{fcc}}$ values for the alloys.

(4) Rolling resulted in an increase in strength and a decrease in ductility of the alloy. For instance, the yield strength of the alloy increased from $545 \mathrm{MPa}$ to $1310 \mathrm{MPa}$ when the rolling reduction changed from $20 \%$ to $80 \%$, while the corresponding uniform elongation values were $18.0 \%$ and $1.3 \%$, respectively.

(5) Analysis of the strengthening mechanisms has revealed that at rolling reductions $<40 \%$ substructure strengthening prevailed, while at strains $>40 \%$ grain (twin) boundary strengthening made the main contribution. At $40 \%$ reduction, both factors contributed equally.

Acknowledgments: This study was supported by Russian Foundation for Basic Research (grant No. 16-38-60061). The authors are also grateful to the personnel of the Joint Research Center, "Technology and Materials", Belgorod State National Research University, for their assistance with the instrumental analysis.

Author Contributions: N.S. and S.Z. conceived and designed the experiments; V.S. fabricated the experimental alloy; M.K., D.S., R.C., and N.Y. performed the experiments; M.K., N.S and S.Z. analyzed the data and wrote the paper.

Conflicts of Interest: The authors declare no conflict of interest.

\section{References}

1. Miracle, D.B.; Senkov, O.N. A critical review of high entropy alloys and related concepts. Acta Mater. 2017, 122, 448-511. [CrossRef]

2. Zhang, Y.; Zuo, T.T.; Tang, Z.; Gao, M.C.; Dahmen, K.A.; Liaw, P.K.; Lu, Z.P. Microstructures and properties of high-entropy alloys. Prog. Mater. Sci. 2014, 61. [CrossRef]

3. Pickering, E.J.; Jones, N.G. High-entropy alloys: A critical assessment of their founding principles and future prospects. Int. Mater. Rev. 2016, 183-202. [CrossRef]

4. Tsai, M.-H.; Yeh, J.-W. High-Entropy Alloys: A Critical Review. Mater. Res. Lett. 2014, 2, 107-123. [CrossRef]

5. Gludovatz, B.; Hohenwarter, A.; Catoor, D.; Chang, E.H.; George, E.P.; Ritchie, R.O. A fracture-resistant high-entropy alloy for cryogenic applications. Science 2014, 345. [CrossRef] [PubMed] 
6. Gludovatz, B.; Hohenwarter, A.; Thurston, K.V.S.; Bei, H.; Wu, Z.; George, E.P.; Ritchie, R.O. Exceptional damage-tolerance of a medium-entropy alloy $\mathrm{CrCoNi}$ at cryogenic temperatures. Nat. Commun. 2016. [CrossRef] [PubMed]

7. Li, D.; Zhang, Y. The ultrahigh charpy impact toughness of forged AlxCoCrFeNi high entropy alloys at room and cryogenic temperatures. Intermetallics 2016, 70, 24-28. [CrossRef]

8. Chuang, M.-H.; Tsai, M.-H.; Wang, W.-R.; Lin, S.-J.; Yeh, J.-W. Microstructure and wear behavior of AlxCo1.5CrFeNi1.5Tiy high-entropy alloys. Acta Mater. 2011, 59, 6308-6317. [CrossRef]

9. Otto, F.; Dlouhý, A.; Somsen, C.; Bei, H.; Eggeler, G.; George, E.P. The influences of temperature and microstructure on the tensile properties of a CoCrFeMnNi high-entropy alloy. Acta Mater. 2013, 61. [CrossRef]

10. He, J.Y.Y.; Wang, H.; Huang, H.L.L.; Xu, X.D.D.; Chen, M.W.W.; Wu, Y.; Liu, X.J.J.; Nieh, T.G.G.; An, K.; $\mathrm{Lu}$, Z.P.P. A precipitation-hardened high-entropy alloy with outstanding tensile properties. Acta Mater. 2016, 102, 187-196. [CrossRef]

11. Li, Z.; Pradeep, K.G.; Deng, Y.; Raabe, D.; Tasan, C.C. Metastable high-entropy dual-phase alloys overcome the strength-ductility trade-off. Nature 2016, 534. [CrossRef] [PubMed]

12. Li, Z.; Tasan, C.C.; Springer, H.; Gault, B.; Raabe, D. Interstitial atoms enable joint twinning and transformation induced plasticity in strong and ductile high-entropy alloys. Sci. Rep. 2017, 7, 40704. [CrossRef] [PubMed]

13. Senkov, O.N.; Wilks, G.B.; Scott, J.M.; Miracle, D.B. Mechanical properties of Nb25Mo25Ta25W25 and $\mathrm{V} 20 \mathrm{Nb} 20 \mathrm{Mo} 20 \mathrm{Ta} 20 \mathrm{~W} 20$ refractory high entropy alloys. Intermetallics 2011, 19, 698-706. [CrossRef]

14. Senkov, O.N.; Senkova, S.V.; Woodward, C.F. Effect of aluminum on the microstructure and properties of two refractory high-entropy alloys. Acta Mater. 2014, 68, 214-228. [CrossRef]

15. Senkov, O.N.; Senkova, S.V.; Woodward, C.; Miracle, D.B. Low-density, refractory multi-principal element alloys of the $\mathrm{Cr}-\mathrm{Nb}-\mathrm{Ti}-\mathrm{V}-\mathrm{Zr}$ system: Microstructure and phase analysis. Acta Mater. 2013, 61, 1545-1557. [CrossRef]

16. Stepanov, N.D.; Shaysultanov, D.G.; Salishchev, G.A.; Tikhonovsky, M.A. Structure and mechanical properties of a light-weight AlNbTiV high entropy alloy. Mater. Lett. 2015, 142, 153-155. [CrossRef]

17. Yurchenko, N.Y.; Stepanov, N.D.; Shaysultanov, D.G.; Tikhonovsky, M.A.; Salishchev, G.A. Effect of Al content on structure and mechanical properties of the AlxCrNbTiVZr $(x=0 ; 0.25 ; 0.5 ; 1)$ high-entropy alloys. Mater. Charact. 2016, 121, 125-134. [CrossRef]

18. Yurchenko, N.Y.; Stepanov, N.D.; Zherebtsov, S.V.; Tikhonovsky, M.A.; Salishchev, G.A. Structure and mechanical properties of B2 ordered refractory AlNbTiVZrx $(x=0-1.5)$ high-entropy alloys. Mater. Sci. Eng. A 2017, 704, 82-90. [CrossRef]

19. Cantor, B.; Chang, I.T.H.; Knight, P.; Vincent, A.J.B. Microstructural development in equiatomic multicomponent alloys. Mater. Sci. Eng. A 2004, 375, 213-218. [CrossRef]

20. Otto, F.; Yang, Y.; Bei, H.; George, E.P.P. Relative effects of enthalpy and entropy on the phase stability of equiatomic high-entropy alloys. Acta Mater. 2013, 61, 2628-2638. [CrossRef]

21. Gludovatz, B.; George, E.P.; Ritchie, R.O. Processing, Microstructure and Mechanical Properties of the CrMnFeCoNi High-Entropy Alloy. JOM 2015. [CrossRef]

22. Otto, F.; Dlouhý, A.; Pradeep, K.G.; Kuběnová, M.; Raabe, D.; Eggeler, G.; George, E.P. Decomposition of the single-phase high-entropy alloy $\mathrm{CrMnFeCoNi}$ after prolonged anneals at intermediate temperatures. Acta Mater. 2016, 112. [CrossRef]

23. Schuh, B.; Mendez-Martin, F.; Völker, B.; George, E.P.P.; Clemens, H.; Pippan, R.; Hohenwarter, A.; Volker, B.; George, E.P.P.; Clemens, H.; et al. Mechanical properties, microstructure and thermal stability of a nanocrystalline CoCrFeMnNi high-entropy alloy after severe plastic deformation. Acta Mater. 2015, 96, 258-268. [CrossRef]

24. Stepanov, N.D.D.; Shaysultanov, D.G.G.; Ozerov, M.S.S.; Zherebtsov, S.V.V.; Salishchev, G.A.A. Second phase formation in the CoCrFeNiMn high entropy alloy after recrystallization annealing. Mater. Lett. 2016, 185, 1-4. [CrossRef]

25. Zhang, Z.; Mao, M.M.; Wang, J.; Gludovatz, B.; Zhang, Z.; Mao, S.X.; George, E.P.; Yu, Q.; Ritchie, R.O. Nanoscale origins of the damage tolerance of the high-entropy alloy CrMnFeCoNi. Nat. Commun. 2015, 6, 10143. [CrossRef] [PubMed]

26. Laplanche, G.; Kostka, A.; Horst, O.M.M.; Eggeler, G.; George, E.P.P. Microstructure evolution and critical stress for twinning in the CrMnFeCoNi high-entropy alloy. Acta Mater. 2016, 118, 152-163. [CrossRef] 
27. Stepanov, N.; Tikhonovsky, M.; Yurchenko, N.; Zyabkin, D.; Klimova, M.; Zherebtsov, S.; Efimov, A.; Salishchev, G. Effect of cryo-deformation on structure and properties of CoCrFeNiMn high-entropy alloy. Intermetallics 2015, 59, 8-17. [CrossRef]

28. Jang, M.J.; Ahn, D.-H.; Moon, J.; Bae, J.W.; Yim, D.; Yeh, J.-W.; Estrin, Y.; Kim, H.S. Constitutive modeling of deformation behavior of high-entropy alloys with face-centered cubic crystal structure. Mater. Res. Lett. 2017, 5, 350-356. [CrossRef]

29. Joo, S.-H.; Kato, H.; Jang, M.J.; Moon, J.; Tsai, C.W.; Yeh, J.W.; Kim, H.S. Tensile deformation behavior and deformation twinning of an equimolar CoCrFeMnNi high-entropy alloy. Mater. Sci. Eng. A 2017, 689, 122-133. [CrossRef]

30. Sun, S.J.; Tian, Y.Z.; Lin, H.R.; Dong, X.G.; Wang, Y.H.; Zhang, Z.J.; Zhang, Z.F. Enhanced strength and ductility of bulk CoCrFeMnNi high entropy alloy having fully recrystallized ultrafine-grained structure. Mater. Des. 2017, 133, 122-127. [CrossRef]

31. Wang, Z.; Baker, I. Interstitial strengthening of a f.c.c. FeNiMnAlCr high entropy alloy. Mater. Lett. 2016, 180. [CrossRef]

32. Wang, Z.; Baker, I.; Cai, Z.; Chen, S.; Poplawsky, J.D.; Guo, W. The effect of interstitial carbon on the mechanical properties and dislocation substructure evolution in Fe40.4Ni11.3Mn34.8Al7.5Cr6 high entropy alloys. Acta Mater. 2016, 120. [CrossRef]

33. Stepanov, N.D.; Yurchenko, N.Y.; Tikhonovsky, M.A.; Salishchev, G.A. Effect of carbon content and annealing on structure and hardness of the CoCrFeNiMn-based high entropy alloys. J. Alloys Compd. 2016. [CrossRef]

34. Stepanov, N.D.; Shaysultanov, D.G.; Chernichenko, R.S.; Yurchenko, N.Y.; Zherebtsov, S.V.; Tikhonovsky, M.A.; Salishchev, G.A. Effect of thermomechanical processing on microstructure and mechanical properties of the carbon-containing CoCrFeNiMn high entropy alloy. J. Alloys Compd. 2017. [CrossRef]

35. Liu, C.M.; Wang, H.M.; Zhang, S.Q.; Tang, H.B.; Zhang, A.L. Microstructure and oxidation behavior of new refractory high entropy alloys. J. Alloys Compd. 2014, 583. [CrossRef]

36. Gwalani, B.; Soni, V.; Lee, M.; Mantri, S.; Ren, Y.; Banerjee, R. Optimizing the coupled effects of Hall-Petch and precipitation strengthening in a Al0.3CoCrFeNi high entropy alloy. Mater. Des. 2017, 121, 254-260. [CrossRef]

37. Liu, W.H.; Yang, T.; Liu, C.T. Precipitation hardening in CoCrFeNi-based high entropy alloys. Mater. Chem. Phys. 2017. [CrossRef]

38. He, J.Y.Y.; Liu, W.H.H.; Wang, H.; Wu, Y.; Liu, X.J.J.; Nieh, T.G.G.; Lu, Z.P.P. Effects of Al addition on structural evolution and tensile properties of the FeCoNiCrMn high-entropy alloy system. Acta Mater. 2014, 62, 105-113. [CrossRef]

39. Stepanov, N.D.; Shaysultanov, D.G.; Tikhonovsky, M.A.; Salishchev, G.A. Tensile properties of the $\mathrm{Cr}-\mathrm{Fe}-\mathrm{Ni}-\mathrm{Mn}$ non-equiatomic multicomponent alloys with different $\mathrm{Cr}$ contents. Mater. Des. 2015, 87, 60-65. [CrossRef]

40. Laplanche, G.; Kostka, A.; Reinhart, C.; Hunfeld, J.; Eggeler, G.; George, E.P. Reasons for the superior mechanical properties of medium-entropy CrCoNi compared to high-entropy CrMnFeCoNi. Acta Mater. 2017. [CrossRef]

41. Liu, S.F.; Wu, Y.; Wang, H.T.; He, J.Y.; Liu, J.B.; Chen, C.X.; Liu, X.J.; Wang, H.; Lu, Z.P. Stacking fault energy of face-centered-cubic high entropy alloys. Intermetallics 2017. [CrossRef]

42. De Cooman, B.C.; Estrin, Y.; Kim, S.K. Twinning-induced plasticity (TWIP) steels. Acta Mater. 2018, 142, 283-362. [CrossRef]

43. Saeed-Akbari, A.; Imlau, J.; Prahl, U.; Bleck, W. Derivation and variation in composition-dependent stacking fault energy maps based on subregular solution model in high-manganese steels. Metall. Mater. Trans. A Phys. Metall. Mater. Sci. 2009, 40, 3076-3090. [CrossRef]

44. Schramm, R.E.; Reed, R.P. Stacking fault energies of seven commercial austenitic stainless steels. Metall. Trans. A 1975, 6, 1345-1351. [CrossRef]

45. Wu, Z.; Parish, C.M.; Bei, H. Nano-twin mediated plasticity in carbon-containing FeNiCoCrMn high entropy alloys. J. Alloys Compd. 2015, 647, 815-822. [CrossRef]

46. Wu, S.W.; Wang, G.; Yi, J.; Jia, Y.D.; Hussain, I.; Zhai, Q.J.; Liaw, P.K. Strong grain-size effect on deformation twinning of an Al0.1CoCrFeNi high-entropy alloy. Mater. Res. Lett. 2017, 5, 276-283. [CrossRef] 
47. Yu, P.F.; Cheng, H.; Zhang, L.J.; Zhang, H.; Jing, Q.; Ma, M.Z.; Liaw, P.K.; Li, G.; Liu, R.P. Effects of high pressure torsion on microstructures and properties of an Al0.1CoCrFeNi high-entropy alloy. Mater. Sci. Eng. A 2016, 655, 283-291. [CrossRef]

48. Senkov, O.N.; Semiatin, S.L. Microstructure and properties of a refractory high-entropy alloy after cold working. J. Alloys Compd. 2015, 649, 1110-1123. [CrossRef]

49. Hou, J.; Zhang, M.; Ma, S.; Liaw, P.K.; Zhang, Y.; Qiao, J. Strengthening in Al0.25CoCrFeNi high-entropy alloys by cold rolling. Mater. Sci. Eng. A 2017, 707, 593-601. [CrossRef]

50. Wang, Z.; Gao, M.C.; Ma, S.G.; Yang, H.J.; Wang, Z.H.; Ziomek-Moroz, M.; Qiao, J.W. Effect of cold rolling on the microstructure and mechanical properties of Al0.25CoCrFe1.25Ni1.25 high-entropy alloy. Mater. Sci. Eng. A 2015, 645, 163-169. [CrossRef]

51. Allain, S.; Chateau, J.P.; Bouaziz, O. A physical model of the twinning-induced plasticity effect in a high manganese austenitic steel. Mater. Sci. Eng. A 2004, 387-389, 143-147. [CrossRef]

52. Cotes, S.M.; Guillermet, A.F.; Sade, M. Fcc/Hcp martensitic transformation in the Fe-Mn system: Part II. Driving force and thermodynamics of the nucleation process. Metall. Mater. Trans. A 2004, 35, 83-91. [CrossRef]

53. Zaddach, A.J.; Scattergood, R.O.; Koch, C.C. Tensile properties of low-stacking fault energy high-entropy alloys. Mater. Sci. Eng. A 2015, 636. [CrossRef]

54. Klimova, M.; Zherebtsov, S.; Stepanov, N.; Salishchev, G.; Haase, C.; Molodov, D.A. Microstructure and texture evolution of a high manganese TWIP steel during cryo-rolling. Mater. Charact. 2017, 132, $20-30$. [CrossRef]

55. Welsch, E.; Ponge, D.; Hafez Haghighat, S.M.; Sandlöbes, S.; Choi, P.; Herbig, M.; Zaefferer, S.; Raabe, D. Strain hardening by dynamic slip band refinement in a high-Mn lightweight steel. Acta Mater. 2016, 116, 188-199. [CrossRef]

56. Haase, C.; Zehnder, C.; Ingendahl, T.; Bikar, A.; Tang, F.; Hallstedt, B.; Hu, W.; Bleck, W.; Molodov, D.A. On the deformation behavior of $\mathrm{k}$-carbide-free and $\mathrm{k}$-carbide-containing high-Mn light-weight steel. Acta Mater. 2017, 122, 332-343. [CrossRef]

57. Wu, Z.; Bei, H.; Pharr, G.M.; George, E.P. Temperature dependence of the mechanical properties of equiatomic solid solution alloys with face-centered cubic crystal structures. Acta Mater. 2014, 81. [CrossRef]

58. Yanushkevich, Z.; Mogucheva, A.; Tikhonova, M.; Belyakov, A.; Kaibyshev, R. Structural strengthening of an austenitic stainless steel subjected to warm-to-hot working. Mater. Charact. 2011, 62, 432-437. [CrossRef]

59. Kusakin, P.S.; Kaibyshev, R.O. High-Mn twinning-induced plasticity steels: Microstructure and mechanical properties. Rev. Adv. Mater. Sci. 2016, 44, 326-360.

60. Kalidindi, S.R.; Salem, A.A.; Doherty, R.D. Role of deformation twinning on strain hardening in cubic and hexagonal polycrystalline metals. Adv. Eng. Mater. 2003, 5, 229-232. [CrossRef] 